\title{
INCREASING THE MECHANICAL PROPERTIES OF DC01 STEEL BY THE DRECE METHOD OF SEVERE PLASTIC DEFORMATION
}

\author{
Pavel SZKANDERA, Marek SADÍLEK, Stanislav RUSZ, Pavel DOSTÁL, Jaroslav DUBSKÝ, \\ Jan ZELINKA, Ondřej KOTÁSEK \\ ${ }^{1}$ VSB - Technical University of Ostrava, Ostrava, Czech Republic, EU, \\ pavel.szkandera@vsb.cz,marek.sadilek@vsb.cz,stanislav.rusz@vsb.cz,dostal.pa@email.cz, \\ jardub@seznam.cz,jan.zelinka@vsb.cz,ondraa06@gmail.com
}

https://doi.org/10.37904/metal.2020.3482

\begin{abstract}
The article is focused on the process of severe plastic deformation (SPD). New method using the SPD principle (DRECE) is described in the article. New method using the severe plastic deformation (DRECE) is particularly suitable for forming metal materials. Materials produced by this technology are characterized by increasing mechanical properties while maintaining sufficient ductility of the materials. In the practical part of the work, experiments were carried out on DC01 steel using the DRECE method. Sheet metal strips were formed through one to seven passes by DRECE method. The thickness of the formed strips was $2 \mathrm{~mm}$, the strips width was $59 \mathrm{~mm}$ and the strips length were $1000 \mathrm{~mm}$. The dimensions of the sheet metal strips were limited only by the design of the forming device using the method severe plastic deformation (DRECE). The experiment was performed on a forming tool with angle in the deformation material zone $108^{\circ}$. The experiment was demonstrated on all sheet metal strips under the same forming conditions. The aim of the experiments was to verify the influence of the number of passes by the forming device on the achieved mechanical properties of the steel. The final part of the article describes the achieved mechanical properties of the sheet metal strip after forming by the DRECE method.
\end{abstract}

Keywords: Severe plastic deformation, DRECE, forming, sheet metal strips, mechanical properties

\section{INTRODUCTION}

Severe plastic deformations are able to utilize ultra-fine-grained structures (UFG structures) and the principal mechanisms of properties of moulded materials by inserting severe plastic deformations into the moulded material. [1-3] Forming processes using severe plastic deformation of material (severe plastic deformation SPD) cause changes in microstructure, mechanical properties and granularity of formed materials. By modelling the evolution of material. The microstructure pattern is determined in two steps. In the first step the deformation of the material at selected points of the material is monitored, these points are created using standard deformation meshes. In this step, curing values are possible materials at each measuring point relatively easy to determine the size of the inserted deformation into the material. In the second step, micromechanical models of plasticity are applied and the microstructure development is analyzed together with the deformation trajectory using points defined in the first step. [4]

\section{EXPERIMENT BY DRECE}

The experiment was performed on a forming machine that uses the DRECE severe plastic deformation process. The DRECE method belongs to a promising group of technologies using severe plastic deformations. The DRECE method is particularly suitable for forming metal materials. This method reduces the grain size of the materials to values of $10 \mu \mathrm{m}$ and lower, depending on the material to be tested. Materials formed by this 
technology are characterized by an increase in mechanical properties. The DRECE method is based on the extruding of metal sheet with a forming tool which produces a forming angle of $108^{\circ}$ or $113^{\circ}$ in the material deformation zone. [5] The device using DRECE is shown in Figure 1.

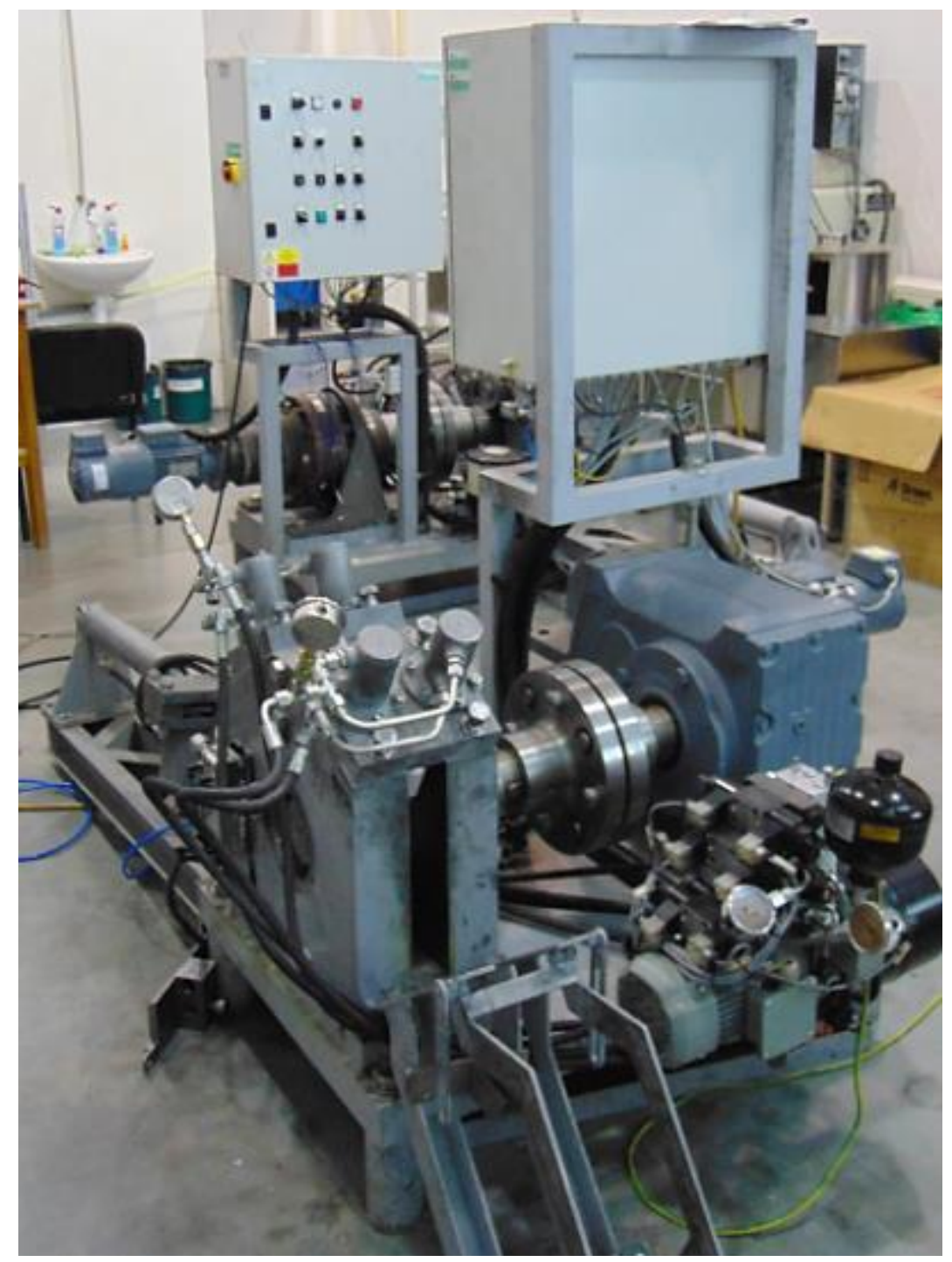

Figure 1 Method DRECE

The DC01 steel strips were extruded by a forming device using the DRECE severe plastic deformation method. The strips were extruded severe times through one to seven passes through the device. The experiment was performed on a forming tool that creates an angle in the material deformation zone of $108^{\circ}$. The experiment was performed on all strips under the same forming conditions. The pressure of the pressure rollers is exerted by means of hydraulic pistons and the equipment of the forming device enables its relatively precise regulation. Due to the maximum efficiency of extrusion of individual strips of sheets, the maximum speed of extrusion of strips $\left(20 \mathrm{~mm} \mathrm{~s}^{-1}\right)$ was set on the forming machine for all passes.

\section{CHARACTERISTICS OF VERIFIED STEEL}

In this work, an experiment was carried out on DC01 steel. This steel is designed for bending, cold flashing or molding production. The chemical composition of the steel was determined by optical emission spectroscopy GDOES. The chemical composition of DC01 steel is shown in Table 1. 
Table 1 Chemical composition of steel DC01

\begin{tabular}{|c|c|c|c|c|c|c|c|c|}
\hline $\begin{array}{c}\text { C } \\
(\%)\end{array}$ & $\begin{array}{l}\text { Mn } \\
(\%)\end{array}$ & $\begin{array}{c}\mathbf{S i} \\
(\%)\end{array}$ & $\begin{array}{c}\mathbf{P} \\
(\%)\end{array}$ & $\begin{array}{c}\mathbf{S} \\
(\%)\end{array}$ & $\begin{array}{l}\mathrm{Cr} \\
(\%)\end{array}$ & $\begin{array}{c}\mathbf{N i} \\
(\%)\end{array}$ & $\begin{array}{l}\text { Mo } \\
(\%)\end{array}$ & $\begin{array}{l}\mathrm{Cu} \\
(\%)\end{array}$ \\
\hline 0.050 & 0.203 & 0.020 & 0.014 & 0.008 & 0.053 & 0.056 & 0.005 & 0.075 \\
\hline $\begin{array}{c}\mathrm{Ti} \\
(\%)\end{array}$ & $\begin{array}{l}\text { Co } \\
\text { (\%) }\end{array}$ & $\begin{array}{c}\text { B } \\
(\%)\end{array}$ & $\begin{array}{l}\mathbf{P b} \\
(\%)\end{array}$ & $\begin{array}{c}\text { V } \\
(\%)\end{array}$ & $\begin{array}{l}\text { W } \\
(\%)\end{array}$ & $\begin{array}{c}\text { Al } \\
\text { (\%) }\end{array}$ & $\begin{array}{l}\mathbf{N b} \\
(\%)\end{array}$ & \\
\hline$<0.001$ & 0.002 & $<0.001$ & $<0.001$ & $<0.001$ & $<0.001$ & 0.050 & $<0.001$ & \\
\hline
\end{tabular}

The Table 2 shows the mechanical properties of DC01 steel guaranteed by the seller of this steel.

Table 2 Mechanical properties of DC01 steel [6]

\begin{tabular}{|c|c|c|c|}
\hline \multirow{2}{*}{ Steel designation } & \multicolumn{3}{|c|}{ Mechanical properties } \\
\cline { 2 - 4 } & $\mathbf{R}_{\mathbf{p 0 . 2}}(\mathbf{M P a})$ & $\mathbf{R}_{\mathbf{m}}(\mathbf{M P a})$ & $\mathbf{A}_{80}(\%)$ \\
\hline DC01 & 280 & $270-410$ & 28 \\
\hline
\end{tabular}

The experiments were carried out on eight strips of DC01 steel sheet. The thickness of the formed strips is 2 $\mathrm{mm}$, the width of the strips is $59 \mathrm{~mm}$ and the length of the strips is $1000 \mathrm{~mm}$. The dimensions of the belts are limited only by the design of the forming machine. By designing the forming equipment, the DRECE method could be used in a wider range of belt dimensions.

\section{MECHANICAL PROPERTIES}

Tensile tests on the DC01 steel strip were performed according to the standard ČSN EN ISO 6892-1 (420310) in the Laboratory of Mechanical Properties of VÚHŽ a. s. Dobrá. The required result of the tensile tests was to determine the resulting mechanical properties of the formed sheets in the initial state and after individual passes through the DRECE forming device. In Table 3. the mechanical properties obtained by performing tensile tests on individual passes are given.

Table 3 Mechanical properties of steel DC01

\begin{tabular}{|c|c|c|c|c|c|}
\hline & \multicolumn{5}{|c|}{ Mechanical properties } \\
\hline Number of passes & $\begin{array}{c}\mathbf{F}_{\mathbf{p} 0.2} \\
(\mathbf{N})\end{array}$ & $\begin{array}{c}\mathbf{F}_{\mathbf{m}} \\
(\mathbf{N})\end{array}$ & $\begin{array}{c}\mathbf{R}_{\mathbf{p} 0.2} \\
(\mathbf{M P a})\end{array}$ & $\begin{array}{c}\mathbf{R} \mathbf{m} \\
(\mathbf{M P a})\end{array}$ & $\begin{array}{c}\mathbf{A}_{\mathbf{8}} \\
(\%)\end{array}$ \\
\hline $0(\mathrm{VS})$ & 22300 & 36500 & 197 & 323 & 66.0 \\
\hline 1 & 32000 & 38000 & 299 & 355 & 40.5 \\
\hline 2 & 33000 & 40500 & 308 & 379 & 29.5 \\
\hline 3 & 35000 & 43000 & 327 & 402 & 27.0 \\
\hline 4 & 35000 & 44000 & 327 & 411 & 22.9 \\
\hline 5 & 39500 & 49000 & 369 & 458 & 21.9 \\
\hline 6 & 36000 & 39000 & 337 & 365 & 20.5 \\
\hline 7 & 38000 & 46500 & 355 & 435 & 19.4 \\
\hline
\end{tabular}

Based on the measured values of mechanical properties steel DC01 shown in Table 3. Figure 2, Figure 3 and Figure 4 were constructed expressing the dependence of mechanical properties on the number of passes of the formed sheet metal sheet through the DRECE forming equipment. 


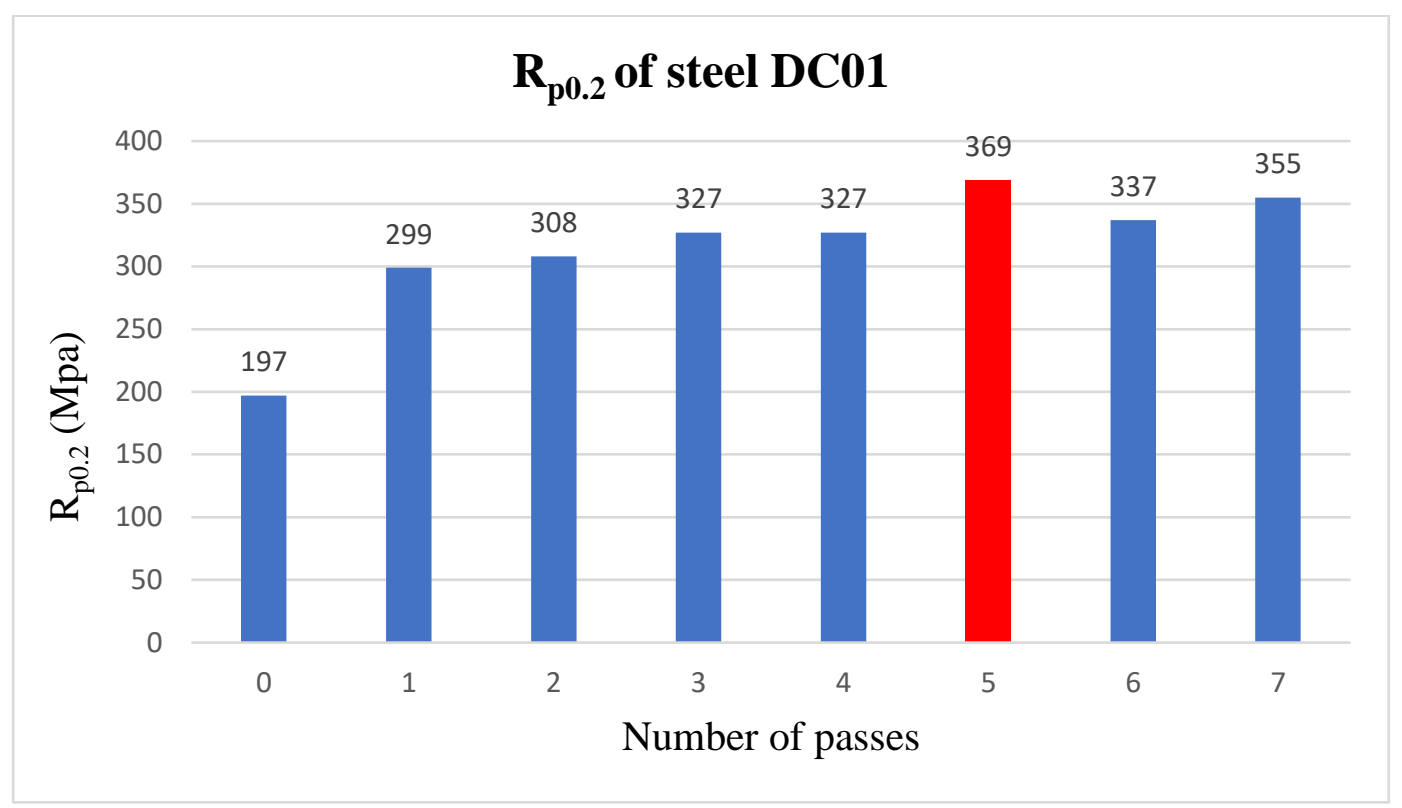

Figure 2 The dependence of $\mathrm{R}_{\mathrm{p} 0.2} \mathrm{DC} 01$ on the number of passes

Figure 2 shows the increase yield strength $\left(R_{p 0.2}\right)$ of DC01 steel after each pass through the DRECE forming machine. The most significant increase in the yield strength occurs after the first pass through the forming device. Yield strength $\left(R_{p 0.2}\right)$ is increased by $102 \mathrm{MPa}(51.8 \%)$ after the $1^{\text {st }}$ pass compared to the initial state of steel. The following passages also shows an increase in $R_{p 0.2}$ but not as marked as after the first pass. The maximum value of yield strength $\left(R_{p 0.2}\right)$ was reached after the $5^{\text {th }}$ passage of steel through the forming machine. After the $5^{\text {th }}$ passage through the forming apparatus, the greatest increase in $\mathrm{Rm}$ compared with the initial state was an increase of $172 \mathrm{MPa}(87 \%)$.

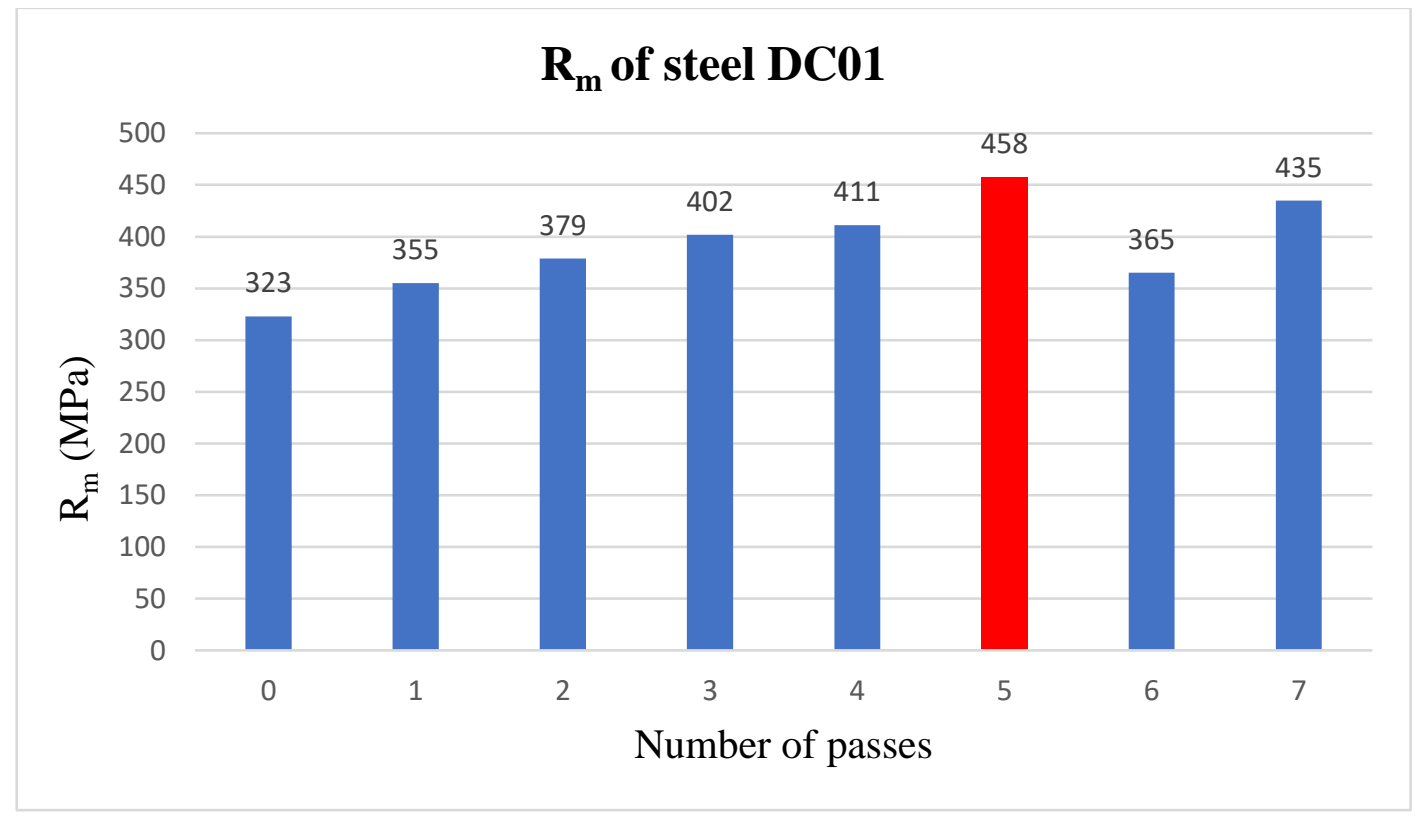

Figure 3 The dependence of $R_{m}$ DC01 on the number of passes

Figure 3 confirms the theoretically expected increase tensile strength $\left(R_{m}\right)$ of DC01 steel after individual passes through the DRECE forming method. The Figure 3 shows the increase in the strength limit up to the 
$5^{\text {th }}$ pass, when its maximum was reached. There was a decrease in $\mathrm{Rm}$ after the $6^{\text {th }}$ pass, and after the $7^{\text {th }}$ pass there is an apparent increase in tensile strength $\left(R_{m}\right)$. The most significant increase of tensile strength $(\mathrm{Rm})$ occurs after the first pass through the forming machine, when was found an increase in $\mathrm{R}_{\mathrm{m}}$ of $32 \mathrm{MPa}$ $(9.9 \%)$ compared to the initial state of the tested steel. After the $5^{\text {th }}$ passage through the forming apparatus, the greatest increase in tensile strength $(\mathrm{Rm})$ compared with the initial state was an increase of $135 \mathrm{MPa}$ (42\%).

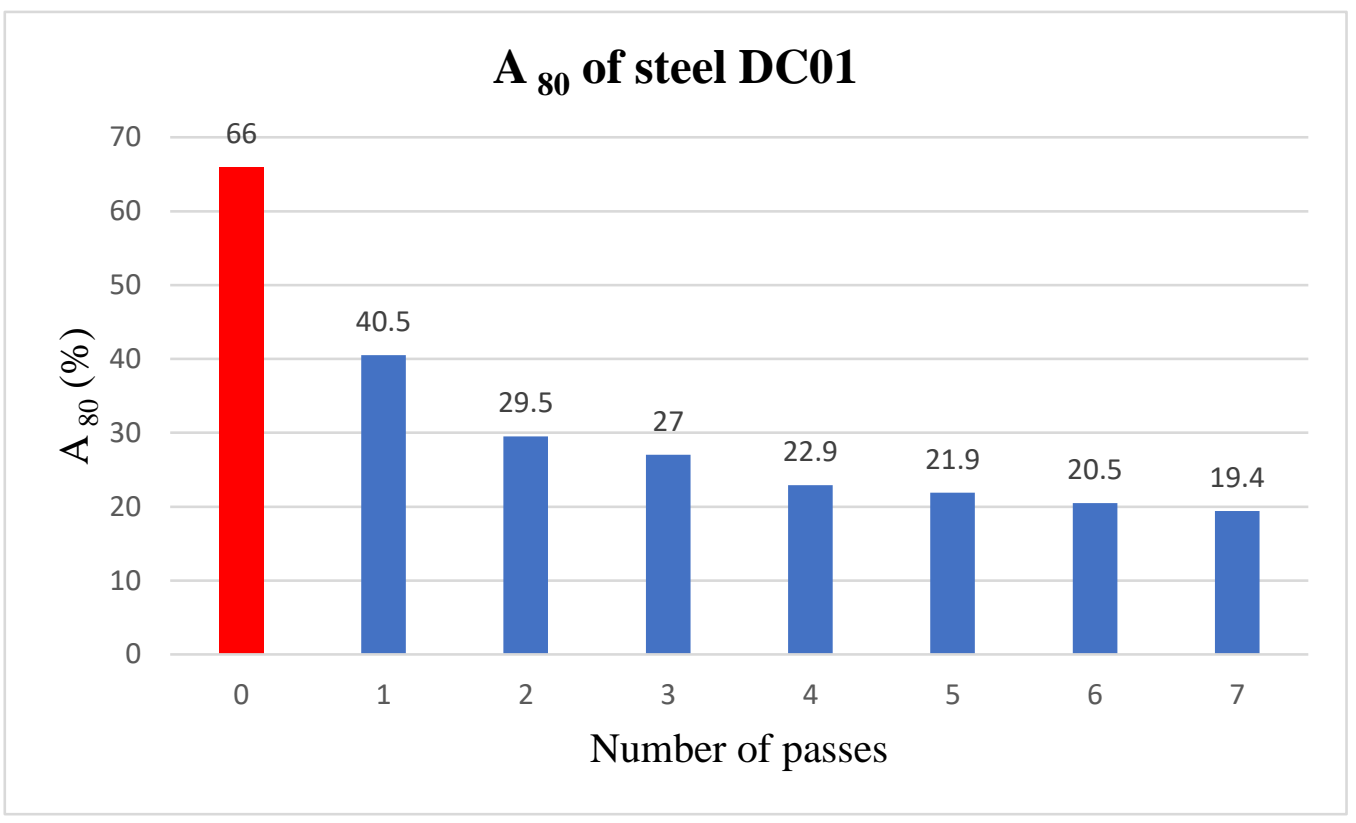

Figure 4 The dependence of A 80 steel DC01 on the number of passes

DC01 steel is primarily intended for cold drawing and cold forming, which confirms the ductility (A80) value of this steel in its initial state. Figure 4 clearly shows that ductility (A80) decline after $1^{\text {st }}$ pass compared to baseline by $25.5 \%$. Despite the negative drop, A80 reaches a very high value after the first pass, which makes the steel very ductile. In the following passes, the ductility (A80) of this steel continuously decreases. Figure 4 shows that for example, the DCEC steel forming of DC01 reduces the ductility (A80) of the steel, but the resulting steel ductility allows it to be used for subsequent forming operations even after the $7^{\text {th }}$ DRECE pass.

\section{CONCLUSION}

Based on the evaluation of experimentally achieved results it was proved that the DRECE method is a method suitable for increasing the mechanical self-steel DC01. Experiments have shown that it is sufficient to perform 1 to 2 passes through a forming tool to achieve a significant increase in mechanical properties. The above knowledge is very important for future use of the DRECE method in industrial practice - because the number of passes of sheet metal through the forming device necessary to achieve the required strength and forming properties reduces production costs and thus increases overall production efficiency.

\section{ACKNOWLEDGEMENTS}

This paper has been completed in association with project Innovative and additive manufacturing technology - new technological solutions for 3D printing of metals and composite materials, reg. no. CZ.02.1.01/0.0/0.0/17_049/0008407 financed by Structural Funds of the European Union and project. 


\section{REFERENCES}

[1] VALIEV, R. Z., ISLAMGALIEV, K., ALEXANDROV, I. V., Bulk nanostructured materials from severe plastic deformation. Progress Mater. Sci, 2000, vol. 45, pp. 103- 89.

[2] VALIEV R. Z., LANGDON, T. G., Principles of equal-channel angular pressing as a processing tool for grain refinement. Progress Mater. Sci. 2006, vol. 51, pp. 881- 981.

[3] BEYERLEIN, I. J., TOTH, L. S,. Texture evolution in equal-channel angular extrusion. Progress Mater. Sci. 2009, vol. 54, pp. 427- 510

[4] GU, C. F., TOTH, L. S., LAPOVOK, R., DAVIES, C. H. J., Texture evolution and grain refinement of ultrafinegrained copper during micro-extrusion. Philos. Mag. 2011, vol. 91, pp. 273- 290

[5] RUSZ, S., CIZEK, L., SALAJKA, M., KEDRON, J., TYLSAR, S., Processing of low Carbon steel by dual rolls equal channel extrusion. Ostrava - Poruba, Czech Republic, 2014. VSB - Technical University of Ostrava.

[6] ALFUN Metal service center: Ocel [online]. [viewed 2018-05-02]. Available from: http://www.alfun.cz/ocel 